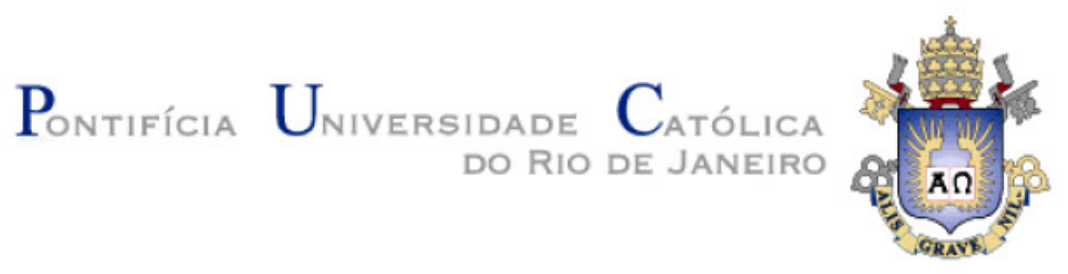

Edelink Efrain Tinoco Falero

Comportamento do fósforo em escórias sintéticas e no pellet feed para redução direta

Dissertação de Mestrado

Dissertação apresentada ao Programa de Pósgraduação em Engenharia de Materiais e Processos Químicos e Metalúrgicos da PUC-Rio como requisito parcial para a obtenção do título de Mestre em Engenharia de Materiais e de Processos Químicos e Metalúrgicos.

Orientador: Prof. José Carlos D’Abreu

Rio de Janeiro

Agosto de 2011 


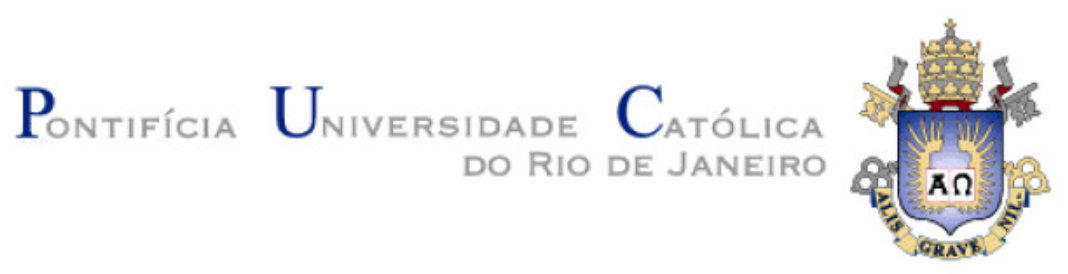

Edelink Efrain Tinoco Falero

\section{Comportamento do fósforo em escórias sintéticas e no pellet feed para redução direta}

Dissertação apresentada como requisito parcial para obtenção do grau de Mestre pelo Programa de Pós-graduação em Engenharia de Materiais e de Processos Químicos e Metalúrgicos da PUC-Rio. Aprovada pela Comissão Examinadora abaixo assinada.

Prof. José Carlos D’Abreu

Orientador

Departamento de Engenharia de Materiais - PUC-Rio

Prof. Helio Marques Kohler

Consultor Independente

Prof. Roberto José de Carvalho

Departamento de Engenharia de Materiais - PUC-Rio

Prof. José Eugênio Leal

Coordenador Setorial do Centro

Técnico Científico - PUC-Rio

Rio de Janeiro, 17 de Agosto de 2011 
Todos os direitos reservados. É proibida a reprodução total ou parcial do trabalho sem autorização da universidade, do autor e do orientador.

\section{Edelink Efrain Tinoco Falero}

Graduou-se em Engenharia Metalúrgica (Universidad Nacional de Ingenieria Lima - Perú, 2005). Trabalhou na companhia Minera Milpo "Cerro Lindo". Sendo responsável pelo laboratório Metalúrgico e área de Filtrado de rejeito da planta Concentradora.

Ficha Catalográfica

Tinoco Falero, Edelink Efrain

Comportamento do fósforo em escórias sintéticas e no pellet feed para redução direta / Edelink Efrain Tinoco Falero; orientador: José Carlos D'Abreu. 2011.

86 f. : il. (color.) ; $30 \mathrm{~cm}$

Dissertação (mestrado)-Pontifícia Universidade Católica do Rio de Janeiro, Departamento de Engenharia de Materiais, 2011.

Inclui bibliografia

1. Engenharia de materiais - Teses. 2. Minérios de ferro. 3. Pelotas. 4. Escórias. 5. Redução direta. I. D'abreu, José Carlos.. II. Pontifícia Universidade Católica do Rio de Janeiro. Departamento de Engenharia de Materiais. III. Título.

CDD: 620.11 
Para Deus, meus pais e irmãos, pelo apoio e confiança. 


\section{Agradecimentos}

Agradeço ao professor Dr. José Carlos D'Abreu, orientador deste trabalho, pela amizade e conselhos ministrados o tempo inteiro.

Ao CNPq e à PUC-Rio, pelos auxílios concedidos, sem os quais este trabalho não Poderia ter sido realizado.

Agradeço ao professor Dr. Helio Marques Kohler pela amizade, conselhos e ensinamentos compartilhados de sua grande experiencia em computação ao serviço deste trabalho.

Agradeço ao Dr. Mauricio Marcos Otaviano pela oportunidade que me foi dada, de fazer parte do projeto, desenvolvido pela Samarco Mineração e a PUC-Rio.

Agradeço ao Engenheiro Raimundo Nonato Filho pelas orientações quanto ao uso dos equipamentos que foram utilizados para realizar os testes.

Agradeço ao professor Dr. Roberto José de Carvalho pela honrosa aceitação em integrar a banca examinadora.

Agradeço a todos os meus amigos e colegas da casa XXI (Hellington, Jeferson e Nildo), pelas sugestões e apoio na redação deste trabalho.

Agradeço a Alexandra e Stephanie, pelo apoio incondicional na redação deste trabalho.

Agradeço a todas as pessoas que direta ou indiretamente, deram alguma contribução neste trabalho, demonstrando mais uma vez que na vida ninguém realiza nada sozinho. 


\section{Resumo}

Tinoco Falero, Edelink Efrain; D’Abreu, José Carlos. Comportamento do fósforo em escórias sintéticas e no pellet feed para redução direta. Rio de Janeiro, 2011. 86p. Dissertação de mestrado - Departamento de Engenharia de Materiais, Pontificia Universidade Católica do Rio de Janeiro.

As pelotas de minério de ferro têm suas propriedades fortemente dependentes da natureza das fases escorificadas que se formam durante o processo de queima. Neste trabalho são apresentados os resultados de uma das pesquisas que compõem o projeto cooperativo entre a Samarco e o Grupo de Siderurgia do DEMa / PUC-Rio, envolvendo a possibilidade de utilização de minérios de ferro portadores de fósforo (pellet feed), na produção de pelotas para redução direta. Com este objetivo foram geradas amostras de escórias sintéticas de mesma composição que as das pelotas RD comerciais, as quais foram submetidas a condições experimentais análogas as do processo industrial. Inicialmente a ciclos térmicos em forno tipo pot-grate e, posteriormente, em escala laboratorial, usando forno de mufla, seguido de etapas de resfriamento em velocidades distintas. Foi possível então constatar que velocidades mais altas de resfriamento, aplicadas na etapa final dos ciclos térmicos, produziam escórias sintéticas sensivelmente amorfas, o que levou a conclusão que as fases escorificadas das pelotas RD também se apresentariam como estruturas não cristalinas. Finalmente, por meio de teste especificamente desenvolvido para a análise seletiva de fósforo em fases oxídicas, conseguiu-se obter uma maior eficiencia na mensuração deste elemento quando dissolvido em escórias amorfas, o que viabilizou a medida das quantidades de fósforo que efetivamente migraram para as mesmas, quando se submetiam as amostras de pellet feed a diferentes temperaturas, variados tempos de residencia e distintas basicidades. Por fim, foi possivel concluir ser o incremento de basicidade do pellet feed um fator de significativa melhoria para o transporte e a dissolução do fósforo pelas escórias, em particular quando submetidos a temperaturas superiores a $900^{\circ} \mathrm{C}$.

\section{Palavras-chave}

Minérios de Ferro; Pelotas; escórias; Redução Direta. 


\section{Abstract}

Tinoco Falero, Edelink Efrain; D’Abreu, José Carlos. Development of a technique to permit the use of iron ores bearing high phosphor content, aiming at competitiveness for the direct reduction market. Rio de Janeiro, 2011. 86p. MSc. Dissertation - Departamento de Engenharia de Materiais, Pontificia Universidade Católica do Rio de Janeiro.

Iron ore pellets have their properties strongly dependent on the nature of the phases present in the slags formed during pelletization. In this work are presented the first results of a research program involving the utilization of phosphorous bearing iron ores in the production of DR pellets (Direct Reduction pellets). Aiming at this, synthetic slags, produced with same composition of the gangue of a commercial DR pellet, were submitted to operational conditions similar to those of the industrial pelletizing process, but performed in a pot-grate reactor and in a laboratory furnace. The obtained slags samples were cooled at different rates, permitting to observe that at high cooling rates the slags obtained were amorphous, suggesting the occurrence of a similar amorphous structure for the slags present in the DR pellets. Finally, tests developed for a selective analysis of phosphorous in oxide phases, showed better efficiency when applied to amorphous slags than in crystalline ones.

Further, the behavior of the phosphor dissolution in the obtained slags during the heating of pellet feed samples was evaluated. In this phase different temperatures, resident times and basicities were tested using a laboratory furnace. The results indicated improvements in the phosphor dissolution with the basicity increase when temperatures above $900^{\circ} \mathrm{C}$ were applied.

\section{Keywords}

Iron Ores; Pellets; slags; Direct Reduction. 


\section{SUMÁRIO}

1. Introdução

2. Objetivos

15

3. Relevância e justificativa

4. Revisão bibliográfica $\quad 20$

4.1. Minerais de Ferro 20

4.1.1. Goethita 20

4.1.2. Hematita 21

4.1.3. Magnetita $\quad 22$

4.2. Ocorrências de fósforo 24

4.2.1. Processos de fixação do fósforo em minério de ferro e solos 25

4.2.2. A influência do fósforo nas propriedades do aço 26

4.3. Aproveitamento do minério de ferro 28

4.3.1 Processo de Pelotização de Minério de Ferro 32

4.3.1.1. Ocorrência de trincas e formação de estrutura duplex na pelota queimada

4.3.2. Influência de alguns elementos químicos na redução dos óxidos

4.3.2.1. Redução de pelotas de hematita na faixa de temperatura entre 900 e $1200^{\circ} \mathrm{C}$

4.3.3. Principais processos de Redução Direta 43

4.3.3.1. Processos Midrex 43

4.3.3.2. Processos HYL

4.3.4. Processos emergentes 48

4.3.4.1. Processo ITmK3 48

4.3.4.2. Processo Fastmet 48 
5. Equipamento e Insumos 50

5.1. Equipamentos 50

5.2. Insumos

6. Procedimentos 53

6.1. Reações químicas durante a queima de pelotas de minério de ferro (conforme a seqüência das fases do processo) 56

6.2. Metodologia da análise seqüencial de dissolução do fósforo das escórias 58

6.3. Modelamento cinético da liberação de fósforo das escórias 59

7. Resultados 61

7.1. Pote grate e forno de mufla 61

7.2. Difração de raios $X \quad 62$

7.3. Seletividade do método qualitativo 66

7.4. Fósforo liberado nas escorias sintéticas 67

$\begin{array}{ll}\text { 7.5. Superficie resposta } & 77\end{array}$

8. Conclusões 79

9. Referências 81

$\begin{array}{ll}\text { Apendice } & 85\end{array}$ 


\section{Lista de figuras}

Figura 1- Diagrama de equilíbrio Fe-O (André Luiz V. da Costa e Silva 2008)

Figura 2 - Faixa granulométrica dos principais produtos da mineração

Figura 3 - Minério de Ferro (pellet feed) 29

Figura 4 - Pelotas aglomeradas cruas $\quad 29$

Figura 5 - Pelotização - fluxograma geral 31

Figura 6 - Forno de grelha móvel (Dwight-Loyd-1940) 32

Figura 7 - Trincas de resiliência, (alta umidade) 37

Figura 8 - Trincas térmicas $\quad 37$

Figura 9 - Fluxograma do processo Midrex® 44

Figura 10 - Fluxograma do processo HYL 46

Figura 11- Forno elétrico de mufla (Combustol) 50

Figura12 - Disco piloto para produção de pelotas cruas. 51

Figura 13 - Pot grate esquema do processo de endurecimento de pelotas 51

Figura 14 - Posicionamento do termopar e do cadinho inox no interior do pot grate 52

Figura 15 - Amostras das misturas dos insumos puros "escória sintética" 52

Figura 16- Perfil térmico no pot grate para o tratamento das escórias sintéticas $\quad 61$

Figura 17 - Difratograma da mistura para produção da escória Sintética

Figura 18 - Difratograma da escória sintética formada no pot grate 63 Figura 19 - Difratograma da escória sintética formada no forno de mufla (40min); resfriamento fora do forno, sem ventilação (20 min) 63 Figura 20 - Difratograma da escória sintética formada no forno de mufla (40min), resfriamento fora do forno, com ventilação forçada (6 min) 
Figura 21 - Difratograma da escória sintética formada no forno de mufla (40min) resfriamento dentro do forno $(20 \mathrm{~h})$

Figura 22 - Difratograma da escória sintética formada no forno de mufla (120min), resfriamento fora do forno, sem ventilação (20 min)

Figura 23 - Difratograma da escória sintética formada no forno de mufla (120 min), resfriamento fora do forno, com ventilação forçada (6 min)

Figura 24 - Difratograma da escória sintética formada no forno de mufla (120 min); resfriamento dentro do forno $(20 \mathrm{~h})$ Figura 25 - Velocidades iniciais de liberação do fósforo 68 Figura 26 - Ajuste dos dados experimentais da análise química da liberação de fósforo das escórias $(B=0,1)$

Figura 27 - Gráfico de Arrhenius $(B=0,1)$, Ea $(\mathrm{kJ} / \mathrm{mol})=47,44 \pm 10 \% 71$ Figura 28 - Ajuste dos dados experimentais da análise química da liberação de fósforo das escórias

Figura 29 - Gráfico de Arrhenius $(B=0,6)$, Ea $(\mathrm{kJ} / \mathrm{mol})=41,17 \pm 5 \% 73$ Figura 30 - Ajuste dos dados experimentais da análise química da liberação de fósforo das escórias 75

Figura 31 - Gráfico de Arrhenius $(B=0,9)$, Ea $(\mathrm{kJ} / \mathrm{mol})=42,55 \pm 4 \% 75$

Figura 32 - Influência da basicidade binária, na energia de ativação aparente

Figura 33 - Superfície resposta da liberação de fósforo das escórias

Figura 34 - Superfície resposta da liberação de fósforo das escórias

Figura 35 - Superfície resposta da liberação de fósforo das escórias

Figura 36 - MEV do teste 2(a), (T으 $=1380 ; B=0,1 ; t$ min $=6,80)$

Figura 37 - MEV do teste $3(b),\left(T^{\circ} \mathrm{C}=1300 ; \mathrm{B}=1 ; \mathrm{t} \min =6,80\right)$ 


\section{Lista de tabelas}

Tabela 1 - Composição da pelota RD comercial 53

Tabela 2 - Composição da ganga da pelota RD comercial 53

Tabela 3 - Composição da escória sintética 53

Tabela 4 - Análise química do pellet feed 55

Tabela 5 - Dados termodinâmicos da decomposição da goethita 56

Tabela 6 - Dados termodinâmicos da decomposição do carbonato de cálcio $\quad 56$

Tabela 7 - Dados termodinâmicos da decomposição do carbonato de Magnesio 56

Tabela 8 - Dados termodinâmicos para a formação de $\mathrm{CaO} . \mathrm{Fe}_{2} \mathrm{O}_{3}$

Tabela 9 - Dados termodinâmicos para a formação de $\mathrm{Ca}(\mathrm{PO}) 257$

Tabela 10 - Dados termodinâmicos para a formação de $\mathrm{CaO}^{-\mathrm{SiO}_{2}} 57$

Tabela 11 - Dados termodinâmicos para a formação de $\mathrm{MgFe}_{2} \mathrm{O}_{4} \quad 57$

Tabela 12 - Dados termodinâmicos para a formação de $\mathrm{MgSiO}_{3} \quad 57$

Tabela 13 - Análise do fósforo nas escórias sintéticas $\quad 67$

Tabela 14 - Análise química da liberação de fósforo das escórias depois do aquecimento do pellet feed $(B=0,1) \quad 70$

Tabela 15 - Análise química da liberação de fósforo das escórias depois do aquecimento do pellet feed $(\mathrm{B}=0,6)$

Tabela 16 - Análise química da liberação de fósforo das escórias depois do aquecimento do pellet feed $(B=0,9) \quad 74$

Tabela 17 - Analises química do teste 2(a), com MEV 86

Tabela 18 - Analises química do teste 3(b), com MEV 86 